\title{
Pengaruh Integrasi Pembelajaran Kooperatif Model Learning Together dan Pemecahan Masalah Kimia dengan Teknik Pathway terhadap Pemahaman Konseptual dan Algoritmik Kimia
}

\author{
Muntari1 \\ 1Teknologi Pembelajaran-Universitas Negeri Malang
}

\section{INFO ARTIKEL}

\section{Riwayat Artikel:}

Diterima: Tgl-Bln-Thn

Disetujui: Tgl-Bln-Thn

\section{Kata kunci: \\ Strategi pembelajaran \\ Eksperimen semu \\ Pemahaman konseptual}

\begin{abstract}
ABSTRAK
Abstract: The purposes of the study to examine the effect of implementation of instructional strategy through LT model of cooperative learning and through direct instruction to student's conceptual and algorithmic understanding, The study used quasi experiment which was pretest-posttest nonequivalent control group design was selected with two factor $2 \times 2$ version measurement technique. The results of the study were as follow: (1) there was no difference in the student's conceptual understanding between group of student employed with LT model of cooperative learning strategy and group of student employed with direct instruction $(\mathrm{F}=2,177, \mathrm{p}=0,142>0,05) ;(2)$ the difference in the student's.
\end{abstract}

\begin{abstract}
Abstrak: Penelitian bertujuan untuk menguji pengaruh penerapan strategi pembelajaran yang dilakukan secara kooperatif model LT dan melalui pembelajaran langsung terhadap pemahaman konseptual dan algoritmik siswa, Penelitian menerapkan eksperimen semu (quasi experiment) di mana rancangan pretest-posttest nonequivalent control group digunakan dengan teknik pengukuran dua faktor versi $2 \times 2$. Hasil penelitian menunjukkan bahwa: (1) tidak ada perbedaan dalam pemahaman konseptual antara kelompok siswa yang belajar dengan menerapkan strategi pembelajaran kooperatif dan kelompok siswa yang belajar dengan menerapkan strategi pembelajaran langsung $(\mathrm{F}=2,177, \mathrm{p}=0,142>0,05)$.
\end{abstract}

\author{
Alamat Korespondensi: \\ Muntari \\ Teknologi Pembelajaran \\ Universitas Negeri Malang \\ Jalan Semarang 5, Malang 65154 \\ E-mail: m_untari@yahoo.co.id
}

Upaya meningkatkan kualitas pendidikan tidak lepas dari upaya memberdayakan potensi siswa sebagai peserta didik dan sebagai masyarakat belajar sebagaimana diamanatkan Undang-undang No 20 tahun 2003 tentang Sistem Pendidikan Nasional bahwa tujuan pendidikan nasional yaitu berkembangnya potensi peserta didik agar menjadi manusia yang beriman dan bertakwa kepada Tuhan Yang Maha Esa, berakhlak mulia, sehat, berilmu, cakap, kreatif, mandiri, dan menjadi warga negara yang demokratis serta bertanggung jawab (Depdiknas, 2003). Untuk itu, pembelajaran yang dilaksanakan di sekolah harus mampu meningkatkan pemberdayaan aktivitas siswa secara keseluruhan. Peraturan Pemerintah Nomor 19 Tahun 2005 tentang Standar Nasional Pendidikan pasal 19 ayat (1) mengamanatkan bahwa proses pembelajaran pada satuan pendidikan diselenggarakan secara interaktif, inspiratif, menyenangkan, menantang, memotivasi peserta didik untuk berpartisipasi aktif, serta memberikan ruang yang cukup bagi prakarsa, kreativitas, dan kemandirian sesuai dengan bakat, minat, dan perkembangan fisik serta psikologis peserta didik (Depdiknas, 2005)

Berdasarkan Permendiknas No 22 Tahun 2006 tentang Standar Isi untuk Satuan Pendidikan Dasar dan Menengah, kelompok mata pelajaran ilmu pengetahuan dan teknologi pada SMA/MA/SMALB dimaksudkan 
untuk memperoleh kompetensi lanjut ilmu pengetahuan dan teknologi serta membudayakan berpikir ilmiah secara kritis, kreatif dan mandiri (Depdiknas, 2006b). Pembelajaran kimia yang dilaksnakan di sekolah sebagai lembaga pendidikan formal harus mampu meningkatkan pemahaman, aktivitas dan kreativitas siswa secara keseluruhan sehingga siswa dapat memahami konsep, prinsip, hukum, dan teori kimia serta saling keterkaitannya dan penerapannya untuk menyelesaikan masalah dalam kehidupan sehari-hari dan teknologi (Depdiknas, 2006b).

Suatu realita sehari-hari, di dalam suatu ruang kelas ketika sesi kegiatan belajar-mengajar (KBM) berlangsung, nampak beberapa atau sebagian besar siswa belum belajar sewaktu guru mengajar. Selama KBM guru belum memberdayakan seluruh potensi dirinya sehingga sebagian besar siswa belum mampu mencapai kompetensi individual yang diperlukan untuk mengikuti pelajaran lanjutan. Beberapa siswa belum belajar sampai pada tingkat pemahaman. Siswa baru mampu mempelajari (baca: menghafal) fakta, konsep, prinsip, hukum, teori, dan gagasan inovatif lainnya pada tingkat ingatan, mereka belum dapat menggunakan dan menerapkannya secara efektif dalam pemecahan masalah sehari-hari yang kontekstual.

Kalau masalah ini dibiarkan dan berlanjut terus, lulusan sebagai generasi penerus bangsa akan sulit bersaing dengan lulusan dari negara-negara lain. Lulusan yang diperlukan tidak sekedar yang mampu mengingat dan memahami informasi tetapi juga yang mampu menerapkannya secara kontekstual melalui beragam kompetensi. Di era pembangunan yang berbasis ekonomi dan globalisasi sekarang ini diperlukan pengetahuan dan keanekaragaman keterampilan agar siswa mampu memberdayakan dirinya untuk menemukan, menafsirkan, menilai dan menggunakan informasi, serta melahirkan gagasan kreatif untuk menentukan sikap dalam pengambilan keputusan.

Ilmu kimia merupakan bagian dari ilmu pengetahuan alam, mempelajari materi yang bersifat abstrak, mikroskopis yang membahas atom, molekul yang tidak tampak, disamping itu mengkaji pula hitungan kimia (Kean \& Middlecamp, 1994). Materi kimia disusun berurutan dari yang paling mendasar atau mudah sampai yang kompleks atau sulit dipahami. Oleh karena itu (Kean \& Middlecamp, 1994) menyatakan bahwa untuk mempelajari kimia membutuhkan kemampuan memorasi, pemahaman konsep dan penerapan operasi matematika. Dalam pembelajaran kimia guru perlu menekankan rasionalisasi obyek-obyek kimia yang mikroskopis, mempelajari konsep-konsep yang bersifat deskriptif disamping hitungan kimia, dan pelajari kimia setiap hari, serta perbaiki jika ada kesalahan pemahaman. Sementara itu (Stamovlasis, Tsaparlis, Kamilatos, Papaoikonomou, \& Zarotiadou, 2005) menambahkan bahwa belajar kimia membutuhkan kemampuan untuk menghubungkan sejumlah fakta, konsep, maupun prinsip, kemampuan operasi matematika, membutuhkan kreativitas, berpikir kritis dan pengetahuan formal.

Keberhasilan belajar kimia sering diukur dari keberhasilan siswa dalam memecahkan masalah kimia yang biasanya diukur melalui tes pemahaman. Pemahaman kimia berdasarkan sifatnya dikategorikan menjadi dua macam, yakni pemahaman konseptual dan pemahaman algoritmik. Pemahaman konseptual didasarkan pada pemahaman teks atau diagram dan membutuhkan siswa melibatkan konsep-konsep dasar dari teori-teori sains. Sedangkan pemahaman algoritmik memerlukan penggunaan serangkaian pemahaman tentang prosedur-prosedur pemecahan masalah termasuk penggunaan rumus matematika (Nakhleh, 1993).

Berkaitan dengan keberhasilan belajar kimia ini, (Hollingworth \& McLoughlin, 2001) menunjukkan bahwa siswa yang mengalami kesulitan menyelesaikan masalah kimia berkaitan dengan rendahnya pengetahuan prosedural/strategi dan keterampilan pemecahan masalah, dan keterampilan berlogika yang terkait dengan masalah yang dihadapi, bukan karena rendahnya pengetahuan dan keterampilan konseptual tentang kimia itu sendiri. Menurut (Nakhleh, 1993), siswa yang mengalami kesulitan memecahkan masalah, di sisi lain, dia sudah memiliki pengetahun konseptual kimia yang cukup, membutuhkan perhatian lebih dari gurunya untuk meningkatkan cara belajarnya dalam kimia. Berdasarkan teori psikologi kognitif, siswa yang memiliki pemahaman konseptual yang cukup akan mampu mengembangkan pemecahan masalah dan juga mempertajam pencarian pemecahan masalah dengan menyesuaikan skema atau kondisi yang diberikan dalam masalah dengan sejumlah aksi dalam memori prosedural yang paling tepat untuk memperoleh hasil yang tepat (Gagne, Yekovish, \& Yekovish, 1993)).

Di sisi lain, sejumlah hasil penelitian terdahulu mengindikasikan bahwa kemampuan siswa dalam pemecahan masalah algoritmik memiliki hubungan yang kecil terhadap pemahaman konseptual kimia (Nakhleh, 1993; Nakhleh \& Mitchell, 1993; Nurrenbern \& Pickering, 1987). Dengan kata lain, penelitian ini menunjukkan bahwa kebanyakan siswa dapat memecahkan masalah algoritmik tetapi hanya memiliki pemahaman kimia yang rendah untuk pemecahan masalah konseptual. Satu penelitian serupa dilakukan di 
Asia (Taiwan) menunjukkan hasil yang mendukung hasil penelitian di atas (Chiu, 2001). Lebih tegas lagi hasil penelitian (Stamovlasis et al., 2005) menunjukkan independensi antara dimensi konseptual dan dimensi algoritmik. Mereka menyimpulkan bahwa kemampuan dalam pemecahan masalah algoritmik mungkin terpisah dengan kemampuan dalam pertanyaan-pertanyaan konseptual.

Berkaitan dengan subyek penelitian, tingkat keberhasilan siswa dalam mata pelajaran kimia secara umum berada di bawah nilai rata-rata mata pelajaran rumpun sain yang lain. Hal ini salah satunya diindikasikan oleh perolehan nilai mata pelajaran kimia pada UMPTN (Depdiknas, 2006a, 2007). Data nilai mata pelajaran kimia yang dihimpun dari beberapa SMA Negeri se-Kota Mataram juga menunjukkan rata-rata nilai mata pelajaran kimia berada di bawah nilai rata-rata mata pelajaran rumpun sain lainnya (Dinas Pendidikan Nasional Kota Mataram, 2007). Ini berarti masih diperlukan upaya peningkatan keberhasilan siswa dalam mata pelajaran kimia.

Sejumlah penelitian mengkaji upaya perbaikan strategi pembelajaran untuk membantu siswa dalam meningkatkan pemahaman, aktivitas dan kreativitas siswa secara keseluruhan sehingga siswa dapat memahami konsep, prinsip, hukum, dan teori kimia serta saling keterkaitannya dan penerapannya. Dalam pembelajaran terkini menekankan pentingnya diskusi dalam suatu kerja kelompok secara kooperatif dalam pengembangan kreativitas pemecahan masalah kimia (Cardellini, 2006; Wood, 2006). Pembelajaran kooperatif adalah suatu metode pembelajaran aktif di mana siswa terlibat dalam beberapa aktivitas. Diskusi dapat meningkatkan belajar lebih aktif sebab dalam diskusi yang efektif siswa dapat: mengekpresikan apa yang telah dipelajari, berpikir kritis tentang pengetahuan dan ide baru, dan berani mengambil keputusan sendiri berdasarkan pengetahuan dan ide barunya. Selain itu diskusi juga dapat meningkatkan kepercayaan diri dan diskusi menjadikan kelompok dinamis, di mana setiap anggota dalam kelompok diskusi ikut terlibat dalam memecahkan masalah.

Berbagai strategi pemecahan masalah telah dikembangkan untuk membantu siswa dalam meningkatkan keterampilan siswa dalam pemecahan masalah kimia. (Wagner, 2001) mengembangkan teknik MFRC (mole ratio flow chart) yang dapat membantu guru dalam pembelajaran stoikiometri reaksi dan membantu siswa dalam pemecahan masalah stoikiometri. (Hollingworth \& McLoughlin, 2001) mengembangkan suatu model sistem on-line untuk mendukung keterampilan metakognitif dalam pemecahan masalah yang diturunkan dari perspektif konstruktivistik dan teori belajar orang dewasa.

(McCalla, 2003) mengembangkan teknik pathway dalam pemecahan masalah kimia yang didasarkan pada bukunya Polya "How to Solve It" (Polya dalam (McCalla, 2003)) tetapi lebih simbolik dan berdomain khusus, mengikuti pendekatan konstruktivistik untuk belajar. Teknik pathway adalah suatu teknik pemecahan masalah kimia yang menuntut siswa mampu menghubungkan satu konsep dengan konsep lainnya untuk memecahkan masalah berdasarkan informasi yang diberikan. Teknik pathway adalah proses empat tahap untuk pemecahan masalah kimia, yaitu: menentukan tujuan, identifikasi informasi yang diberikan, membuat alur (pathway) pemecahan, dan menyelesaikan untuk mendapat jawaban.

Sebagaimana pandangan konstruktivis, bahwa siswa harus secara individu menemukan dan mentransfer informasi-informasi kompleks apabila mereka harus menjadikan informasi itu miliknya sendiri (Brooks \& Brooks, 1999). Tujuan utama dari pendekatan teori ini adalah agar siswa mampu mengkonstruk pengetahuannya sendiri melalui cara-cara atau strategi yang dirancang oleh guru dengan memanfaatkan sumber-sumber yang ada. Pendekatan pembelajaran berlandaskan teori konstruktivisme yang telah dikembangkan, salah satunya adalah pembelajaran kooperatif, berdasarkan teori bahwa siswa lebih mudah menemukan dan memahami konsep-konsep yang sulit jika mereka saling mendiskusikan masalah tersebut dengan temannya.

Pembelajaran kooperatif model Learning Together (LT) telah menunjukkan kesuksesan yang tinggi. (Burron, James, \& Ambrosio, 1993) telah menggunakan pembelajaran kooperatif model LT untuk pembelajaran sain dan menghasilkan meningkatnya keterampilan kolaboratif siswa. Keterampilan kolaboratif sangat diperlukan oleh siswa dalam pemecahan masalah sain seperti dalam kimia yang memerlukan pemikiran dari berbagai aspek (Carpenter \& McMillan, 2003; Pratt, 2003).

Penerapan strategi pembelajaran kooperatif model LT dalam pembelajaran pemecahan masalah kimia dengan teknik pathway diduga dapat meningkatkan pemahaman konseptual maupun algoritmik kimia siswa. Siswa diharapkan mampu mengembangkan kemampuan pemecahan masalah kimia melalui diskusi dalam kelompok-kooperatif dengan menerapkan teknik pathway. 
Berdasarkan latar belakang di atas, penelitian ini bertujuan untuk mengetahui pengaruh integrasi pembelajaran kooperatif model LT dan pemecahan masalah kimia dengan teknik pathway terhadap pemahaman konseptual dan algoritmik kimia siswa SMA Kota Mataram.

\section{METODE}

Penelitian ini dilakukan di SMA Negeri 1 Mataram pada siswa kelas XI semester genap tahun ajaran 2007/2008. Dalam penelitian ini, materi pelajaran difokuskan pada pokok bahasan "Asam-Basa dan Penerapannya dalam Hitungan Kimia”.

Penelitian ini merupakan penelitian eksperimen semu (quasi experiment) yang bertujuan untuk menguji pengaruh variabel bebas terhadap variabel terikat. Variabel bebas dalam penelitian ini adalah strategi pembelajaran, yang terdiri atas pembelajaran kooperatif model LT dan pembelajaran langsung. Pemecahan masalah kimia dengan teknik pathway sebagai variabel kontrol diterapkan pada kedua kelompok strategi pembelajaran. Sedangkan variabel terikatnya adalah pemahaman konseptual dan pemahaman algoritmik kimia siswa. Subjek penelitian terdiri dari 2 kelompok belajar yaitu kelas XI IPA-2 dan XI IPA-6 (pembelajaran kooperatif model LT) dan kelas XI IPA-3 dan XI IPA-5 (pembelajaran langsung). Rancangan penelitian disajikan pada Tabel 1.

Tabel 1 Rancangan Penelitian

\begin{tabular}{ccc}
\hline Jenis Variabel & $\begin{array}{c}\text { Pembelajaran } \\
\text { Kooperatif }\end{array}$ & $\begin{array}{c}\text { Pembelajaran } \\
\text { Langsung }\end{array}$ \\
\hline Pengukuran awal & Ya & Ya \\
Perlakuan Eksperimen & Ya & Ya \\
Pengukuran akhir (THB) & Ya & Ya \\
\hline
\end{tabular}

Adapun teknik pengumpulan data menggunakan tes berupa tes pemahaman konseptual dan algoritmik kimia yang telah diuji validitas dan reliabilitasnya. Selanjutnya data hasil penelitian dianalisis menggunakan One-way Analysis of Variance (ANOVA) pada taraf signifikansi 5\% (Hair, Anderson, Tatham, \& Black, 1995; Santoso, 2005). Analisis statistik menggunakan perangkat SPPS 10 for Windows XP.

\section{HASIL}

Kelas yang ditetapkan sebagai kelompok eksperimen adalah kelas XI IPA-2, XI IPA-3, XI IPA-5, dan XI IPA-6. Pemilihan keempat kelas eksperimen ini didasarkan pada homogenitas kemampuan awal mata pelajaran kimia dari tiga semester sebelumnya. Pemilihan kelas ini didasakan pada pengaturan distribusi mengajar di SMA Negeri 1 Mataram, dimana guru pengajar dalam penelitian ini mengajar di kelas yang bersangkutan.

Sebelum penerapan perlakuan pembelajaran, siswa diberikan pretes untuk mengukur kemampuan awal siswa mengenai materi yang akan dipelajari selama penelitian (Tabel 2). Uji multivariat untuk menguji kesamaan kelompok dalam pemahaman konseptual dan algoritmik kimia hasil pretes dari kelompok siswa dengan strategi pembelajaran yang berbeda menunjukkan nilai Pillai's Trace, Wilk's Lambda, Hotelling's Trace, Roy's Largest Root masing-masing sebesar 0,007; 0,993; 0,007; dan 0,007 dengan nilai F sebesar 0,608 memiliki angka-angka signifikansi masing-masing 0,545. Angka-angka signifikansi ini jauh lebih besar dari 0,05. Dengan demikian dapat disimpulkan bahwa tidak ada perbedaan pemahaman konseptual dan pemahaman algoritmik kimia secara bersama-sama untuk kelompok dengan strategi pembelajaran yang berbeda.

Tabel 2. Skor Rata-Rata dan Standar Deviasi Pemahaman Konseptual dan Algoritmik Pretes

\begin{tabular}{ccccc}
\hline Variabel & \multicolumn{2}{c}{ Pembelajaran Kooperatif } & \multicolumn{2}{c}{ Pembelajaran Langsung } \\
& Konseptual & Algoritmik & Konseptual & Algoritmik \\
\hline Subjek & 91 & 91 & 91 & 91 \\
Rata-rata & 27,92 & 20,68 & 28,88 & 20,64 \\
Standar Deviasi & 6,94 & 6,66 & 7,06 & 5,92 \\
\hline
\end{tabular}

Setelah diberikan perlakuan pembelajaran selama penelitian, yaitu kelas XI IPA-2 dan XI IPA-6 diterapkan pembelajaran kooperatif model LT yang diintegrasikan dengan pemecahan masalah kimia dengan teknik 
pathway, sedangkan kelas XI IPA-3 dan XI IPA-5 diterapkan pembelajaran langsung yang diintegrasikan dengan pemecahan masalah kimia dengan teknik pathway, hasil postes ditunjukkan pada Tabel 3.

\begin{tabular}{|c|c|c|c|c|}
\hline \multirow[t]{2}{*}{ Variabel } & \multicolumn{2}{|c|}{$\begin{array}{c}\text { Pembelajaran } \\
\text { Kooperatif }\end{array}$} & \multicolumn{2}{|c|}{$\begin{array}{c}\text { Pembelajaran } \\
\text { Langsung }\end{array}$} \\
\hline & $\begin{array}{c}\text { Konseptu } \\
\text { al }\end{array}$ & Algoritmik & $\begin{array}{c}\text { Konseptu } \\
\text { al }\end{array}$ & $\begin{array}{c}\text { Algoritmi } \\
k\end{array}$ \\
\hline Subjek & 91 & 91 & 91 & 91 \\
\hline Rata-rata & 67,617 & 62,794 & 64,973 & 47,292 \\
\hline Standar Deviasi & 12,737 & 14,879 & 12,090 & 13,546 \\
\hline
\end{tabular}

Hasil uji ANOVA pengaruh variabel bebas strategi pembelajaran terhadap pemahaman konseptual kimia, diperoleh nilai statistik $\mathrm{F}=2,063$ dengan angka signifikansi 0,153. Angka signifikansi ini lebih besar dari 0,05. Dengan demikian dapat disimpulkan "tidak ada perbedaan skor rata-rata pemahaman konseptual kimia antara kelompok strategi pembelajaran kooperatif model LT dan pembelajaran langsung”. Hasil uji ANOVA pengaruh variabel bebas strategi pembelajaran terhadap pemahaman algoritmik kimia, diperoleh nilai statistik F = 54,015 dengan angka signifikansi 0,000. Angka signifikansi ini lebih kecil dari 0,05. Dengan demikian dapat disimpulkan "ada perbedaan skor rata-rata pemahaman algoritmik kimia antara kelompok strategi pembelajaran kooperatif model LT dan pembelajaran langsung”. Skor rata-rata pemahaan algoritmik kimia kelompok pembelajaran koopratif model LT $(\mathrm{M}=62,794)$ secara statistik lebih tinggi dibandingkan dengan kelompok pembelajaran langsung $(\mathrm{M}=47,292)$.

\section{PEMBAHASAN}

\section{Pengaruh Strategi Pembelajaran terhadap Pemahaman Konseptual Kimia}

Hasil penelitian menunjukkan bahwa penerapan strategi pembelajaran kooperatif model LT terbukti tidak memberikan perbedaan dalam pemahaman konseptual kimia siswa dibandingkan dengan penerapan pembelajaran langsung. Berdasarkan komparasi secara teoritik dan operasional empirik terhadap strategi pembelajaran yang diterapkan, tampak bahwa kedua strategi pembelajaran menyediakan fasilitas yang sama yaitu penerapan pemecahan masalah kimia dengan teknik pathway. Pemecahan masalah kimia dengan teknik pathway menuntut siswa membangun suatu pathway yang logis dengan menghubungkan apa yang telah mereka ketahui, dimulai dari apa yang ditanyakan (McCalla, 2003). Untuk membangun suatu pathway yang logis diperlukan pengetahuan awal yang mendukung pembentukan tahap-demi-tahap pemecahan masalah yang akan dilakukan kemudian. Agar siswa dapat membangun pathway yang logis, siswa harus mampu menghubungkan skemata konsep-konsep yang berhubungan dengan cara menggali kembali pengetahuan tentang konsep sebelumnya yang berkaitan dengan masalah yang akan dipecahkan.

Atas dasar kajian teoritis tentang pembelajaran kimia dengan menerapkan pemecahan masalah kimia dengan teknik pathway dapat disimpulkan bahwa pemahaman konseptual kimia siswa lebih banyak dipengaruhi oleh teknik pemecahan masalah kimia yang diterapkan dalam penelitian ini. Siswa baik dari kelompok pembelajaran kooperatif maupun kelompok pembelajaran langsung, keduanya menerapkan pemecahan masalah kimia dengan teknik pathway. Siswa yang terbiasa dengan belajar memecahkan masalah dengan cara seperti ini akan dapat mengingat dan menghubungkan materi-materi kimia yang berkaitan sehingga siswa akan memahami konsep-konsep kimia secara utuh.

Pemahaman konsep Asam-Basa membutuhkan pengetahuan kimia sebelumnya yang cukup. Misalnya, untuk memahami karakteristik asam menurut teori Arrhenius, siswa diharuskan memahami bagaimana molekul asam itu terbentuk, dari unsur-unsur apa saja dia terbentuk, dan ion-ion apa saja yang akan dihasilkan jika dilarutkan di dalam air. Untuk dapat menjawab permasalahan ini, siswa membutuhkan pengetahuan tentang ikatan kimia yang baik, konsep bilangan oksidasi, memahami sifat-sifat unsur, dan konsep ionisasi. Dengan demikian, siswa yang telah memiliki kesiapan konseptual yang baik akan mampu menghubungkan permasalahan yang dihadapi dengan pengetahuan sebelumnya. Faktor lain yang mempengaruhi belum maksimalnya hasil pembelajaran dengan pendekatan kooperatif dibandingkan dengan pembelajaran langsung adalah kebiasaan siswa yang sering mengikuti pembelajaran konvensional, yaitu banyak menerima penjelasan dari guru. Biasanya siswa akan lebih mudah memahami materi yang bersifat 
konseptual dari penjelasan guru secara detail. Hal ini dapat diperoleh siswa dari pembelajaran langsung, dan tidak dari pembelajaran kelompok.

Selain itu, berdasarkan sifat pelajaran kimia masih cocok diajarkan dengan strategi pembelajaran langsung (Lucks, 1999). Sejumlah konsep kimia masih memerlukan penjelasan secara rinci dari guru agar tidak menimbulkan penafsiran yang salah dari siswa. Dalam pembelajaran kimia dibutuhkan kemampuan siswa untuk menghubungkan satu konsep dengan konsep lainnya dan membutuhkan keterampilan siswa dalam menyetarakan persamaan reaksi dan pengoperasian matematika. Tuntutan ini perlu mendapat bimbingan dan perhatian terus-menerus dari guru.

\section{Pengaruh Strategi Pembelajaran terhadap Pemahaman Algoritmik Kimia}

Hasil penelitian menunjukkan bahwa penerapan strategi pembelajaran kooperatif model LT terbukti memberikan perbedaan yang signifikan dalam pemahaman algoritmik kimia siswa dibandingkan dengan penerapan strategi pembelajaran langsung. Pencapaian pemahaman algoritmik kimia siswa pada kelompok pembelajaran kooperatif model LT lebih tinggi dibandingkan dengan kelompok siswa dengan penerapan strategi pembelajaran langsung. Kemudian muncul pertanyaan, mengapa dalam pencapaian pemahaman algoritmik kimia penerapan strategi pembelajaran kooperatif model LT lebih tinggi dibandingkan dengan penerapan strategi pembelajaran langsung?

Secara umum hasil penelitian sejak tahun 1990-an menunjukkan bahwa kesulitan siswa memecahkan masalah kimia berkaitan dengan rendahnya pengetahuan prosedural/strategi dan keterampilan pemecahan masalah, dan keterampilan berlogika yang terkait dengan masalah yang dihadapi, bukan karena rendahnya pengetahuan konseptual tentang kimia itu sendiri (Hollingworth \& McLoughlin, 2001). Oleh karena penyelesaian masalah kimia yang bersifat algoritmik membutuhkan sejumlah pengetahuan konseptual dan prosedural, maka dengan kerja kelompok diskusi secara kolaborasi siswa dapat meningkatkan kemampuan pemecahan masalah kimia yang bersifat kompleks.

Strategi pembelajaran kooperatif didasarkan pada teori bahwa siswa lebih mudah menemukan dan memahami konsep-konsep yang sulit jika mereka saling mendiskusikan masalah tersebut dengan temannya (Slavin, 1997). Pembelajaran kooperatif model LT dikembangkan oleh David dan Roger Johnson berdasarkan pada teori psikologi sosial Morton Deutsch dan dari teori motivasional Kurt Lewin (Johnson \& Johnson, 1989). Siswa bekerja dalam kelompok kecil untuk menghasilkan suatu proyek kelompok. Konsep kunci pembelajaran kooperatif model LT adalah "interdependence". Interdependence menekankan persepsi orang bagaimana mereka mempengaruhi dan dipengaruhi oleh apa yang terjadi pada yang lain (Jacobs, Ball, \& Gan, 1997).

Pembelajaran kooperatif model LT telah menunjukkan kesuksesan yang tinggi. Burron et al (1993) telah menggunakan teknik LT untuk pembelajaran sain dan menghasilkan meningkatnya keterampilan kolaboratif siswa. Keterampilan kolaboratif sangat diperlukan oleh siswa dalam pemecahan masalah sain seperti dalam kimia yang memerlukan pemikiran dari berbagai aspek (Carpenter \& McMillan, 2003; Pratt, 2003).

Strategi pembelajaran langsung adalah metode pembelajaran dari paradigma transmisi, dan didasarkan pada teori belajar behaviorisme dan teori perkembangan (Lucks, 1999). Dalam pembelajaran langsung: guru biasanya menggunakan beberapa waktu untuk memberikan penjelasan (ceramah); guru memberi contoh pemecahan masalah kompleks; kemudian siswa diberikan masalah, satu-demi-satu, siswa memecahkan masalah itu atas bimbingan guru; akhirnya, siswa diberikan sejumlah masalah untuk diselesaikan sendiri. Penerapan strategi pembelajaran langsung adalah pembelajaran konvensional yang biasa digunakan seharihari yang lebih bersifat individual. Dalam proses pembelajarannya, siswa tidak mendapat banyak kesempatan untuk berargumentasi dan bertukar pikiran dengan temannya, sehingga menjadi semakin menyulitkan bagi siswa yang tidak memiliki pengetahuan awal yang cukup tentang materi yang dipelajarinya untuk mengembangkan diri.

Konsisten dengan hasil penelitian ini, sejumlah penelitian menunjukkan keunggulan dari strategi pembelajaran kooperatif dalam pemecahan masalah (Cardellini, 2006; Sudyana, 2006; Williamson \& Rowe, 2002; Wood, 2006) menguji keunggulan pembelajaran generatif dalam seting pembelajaran kooperatif dibandingkan dengan pembelajaran konvensional dalam meningkatkan pencapaian pemahaman algoritmik kimia siswa. Hasil penelitian ini menunjukkan bahwa pendekatan seting belajar kooperatif yang diimplementasikan berpengaruh signifikan terhadap pencapaian pemahaman algoritmik kimia siswa. Pengalaman banyak pembelajaran yang menggunakan strategi pembelajaran kooperatif dilaporkan bahwa terjadinya peningkatan keterampilan interpersonal dan komunikasi (Lonning, 1993; Orlich, Harder, Callahan, 
Trevisan, \& Brown, 2012), dan diversifikasi keterampilan pemecahan masalah (Heller, Keith, \& Anderson, 1992).

Dari berbagai kajian teoritis dan empiris di atas sangat mendukung fakta penelitian yang menunjukkan bahwa kemampuan pemecahan masalah kimia, khususnya yang bersifat algoritmik, siswa yang mengikuti pembelajaran kooperatif lebih baik daripada siswa yang mengikuti pembelajaran langsung. Hal ini dapat dijelaskan bahwa siswa dalam menyelesaikan suatu masalah kimia dalam kelompok kooperatif akan saling berbagi (sharing) pemahaman, berargumentasi, belajar dari teman kelompoknya, dan pada akhirnya mampu meningkatkan kemampuan individualnya. Dalam memecahkan masalah kimia dalam kelompok kooperatif, siswa yang telah memiliki pemahaman konsep yang terkait dengan masalah akan menyampaikan kepada kelompok, anggota yang lain mungkin akan menerimanya atau mungkin akan berargumentasi atas permasalahan yang dihadapi menurut pendapatnya, selanjutnya kelompok akan mengambil kesepakatan untuk suatu jawaban atas permasalahn tertentu. Dalam proses pemecahan masalah seperti ini, akan meningkatkan kemampuan pemecahan masalah secara individual bagi semua anggota kelompoknya, termasuk kemampuan dalam pemecahan masalah algoritmik kimia.

\section{SIMPULAN DAN SARAN}

\section{Simpulan}

Pelajaran kimia termasuk materi yang kompleks, selain bersifat abstrak dan banyak berhubungan dengan konsep-konsep lain, di dalamnya juga terdapat banyak masalah yang bersifat matematis, yang termasuk dalam kategori ill-structured. Untuk itu dalam rangka peningkatan kemampuan pemecahan masalah perlu diupayakan pendekatan pembelajaran yang mampu meningkatkan keterampilan siswa dalam menyelesaikan masalah.

Berdasarkan hasil penelitian ini dapat disimpulkan bahwa penerapan integrasi strategi pembelajaran kooperatif model LT dan pemecahan masalah kimia dengan teknik pathway terbukti tidak menunjukkan adanya perbedaan pemahaman konseptual kimia siswa apabila dibandingkan dengan pembelajaran langsung. Sementara, penerapan integrasi strategi pembelajaran kooperatif model LT dan pemecahan masalah kimia dengan teknik pathway terbukti dapat meningkatkan pemahaman algoritmik kimia siswa secara signifikan apabila dibandingkan dengan pembelajaran langsung.

\section{Saran}

Berdasarkan hasil penelitian ini disarankan kepada guru mata pelajaran kimia untuk menerapkan pembelajaran kooperatif secara terencana, misalnya dengan memberikan lembar kerja siswa (LKS) sebagai bahan diskusi siswa. Contoh desain pembelajaran dan perangkat pembelajaran yang terkait dengan penelitian ada pada penulis, dan dapat dikembangkan oleh pemakai.

Untuk maksud agar lebih dapat menjawab permasalahan yang belum terjawab dalam penelitian ini, disarankan untuk melakukan penelitian lanjutan dengan melibatkan variabel lain misalnya kemampuan matematika siswa atau melibatkan lebih banyak kelompok siswa dan guru mata pelajaran kimia.

\section{DAFTAR RUJUKAN}

Brooks, J. G., \& Brooks, M. G. (1999). In search of understanding: The case for constructivist classrooms. ASCD.

Burron, B., James, M. L., \& Ambrosio, A. L. (1993). The effects of cooperative learning in a physical science course for elementary/middle level preservice teachers. Journal of Research in Science Teaching, 30(7), 697-707.

Cardellini, L. (2006). Fostering creative problem solving in chemistry through group work. Chemistry Education Research and Practice, 7(2), 131-140.

Carpenter, S., \& McMillan, T. (2003). Incorporation of a cooperative learning technique in organic chemistry. Journal of Chemical Education, 80(3), 330.

Chiu, M. H. (2001). Algorithmic problem solving and conceptual understanding of chemistry by students at a local high school in Taiwan. Proceedings-National Science Council Republic of China Part D Mathematics Science and Technology Education, 11(1), 20-38.

Depdiknas. (2003). Undang-undang No 20 tahun 2003 tentang Sistem Pendidikan Nasional.

Depdiknas. (2005). Peraturan Pemerintah Nomor 19 Tahun 2005 tentang Standar Nasional Pendidikan. 
Depdiknas. (2006a). Hasil Seleksi Ujian Masuk Perguruan Tinggi Negeri Tahun 2006.

Depdiknas. (2006b). Peraturan Menteri Pendidikan Nasional RI nomor 22 Tahun 2006 tentang Standar Isi untuk Satuan Pendidikan Dasar dan Menengah. Jakarta.

Depdiknas. (2007). Hasil Seleksi Ujian Masuk Perguruan Tinggi Negeri Tahun 2007.

Dinas Pendidikan Nasional Kota Mataram. (2007). Data Nilai Hasil Ujian Akhir SMA se-Kota Mataram.

Gagne, E. D., Yekovish, C. W., \& Yekovish, F. R. (1993). The Cognitive Psychology of School Learning. Harper Collins College.

Hair, J. F., Anderson, R. E., Tatham, R. L., \& Black, W. C. (1995). Multivariate date analysis with readings. Englewood Cliff, NJ: Prentce.

Heller, P., Keith, R., \& Anderson, S. (1992). Teaching problem solving through cooperative grouping. Part 1: Group versus individual problem solving. American Journal of Physics, 60(7), 627-636.

Hollingworth, R. W., \& McLoughlin, C. (2001). Developing science students' metacognitive problem solving skills online. Australasian Journal of Educational Technology, 17(1).

Jacobs, G. M., Ball, J., \& Gan, S. L. (1997). Learning cooperative learning via cooperative learning: A sourcebook of lesson plans for teacher education on cooperative learning. Kagan Cooperative Learning.

Johnson, D. W., \& Johnson, R. T. (1989). Cooperation and competition: Theory and research. Interaction Book Company.

Kean, E., \& Middlecamp, C. (1994). How to survive (and even excel in) general chemistry. McGraw-Hill Companies.

Lonning, R. A. (1993). Effect of cooperative learning strategies on student verbal interactions and achievement during conceptual change instruction in 10th grade general science. Journal of Research in Science Teaching, 30(9), 10871101.

Lucks, R. (1999). Constructivist teaching vs direct instruction. $P$ Ape $R$.

McCalla, J. (2003). Problem solving with pathways. Journal of Chemical Education, 80(1), 92.

Nakhleh, M. B. (1993). Are our students conceptual thinkers or algorithmic problem solvers? Identifying conceptual students in general chemistry. Journal of Chemical Education, 70(1), 52.

Nakhleh, M. B., \& Mitchell, R. C. (1993). Concept learning versus problem solving: There is a difference. ACS Publications.

Nurrenbern, S. C., \& Pickering, M. (1987). Concept learning versus problem solving: Is there a difference? Journal of Chemical Education, 64(6), 508.

Orlich, D. C., Harder, R. J., Callahan, R. C., Trevisan, M. S., \& Brown, A. H. (2012). Teaching strategies: A guide to effective instruction. Cengage Learning.

Pratt, S. (2003). Cooperative learning strategies. The Science Teacher, 70(4), 25.

Santoso, S. (2005). Menguasai statistik di era informasi dengan SPSS 12. Elex Media Komputindo.

Slavin, R. E. (1997). Educational Technology: Theory and Practice (5th ed.). Boston: Allyn \& Bacon.

Stamovlasis, D., Tsaparlis, G., Kamilatos, C., Papaoikonomou, D., \& Zarotiadou, E. (2005). Conceptual understanding versus algorithmic problem solving: Further evidence from a national chemistry examination. Chemistry Education Research and Practice, 6(2), 104-118.

Sudyana, I. N. (2006). Pengaruh Model Pembelajaran Generatif Melalui Seting Belajar Kooperatif Terhadap Pemahaman Konseptual dan Algoritmik Kimia Siswa Kelas 2 Sekolah Menengah Atas. Universitas Negeri Malang.

Wagner, E. P. (2001). A study comparing the efficacy of a mole ratio flow chart to dimensional analysis for teaching reaction stoichiometry. School Science and Mathematics, 101(1), 10-22.

Williamson, V. M., \& Rowe, M. W. (2002). Group problem-solving versus lecture in college-level quantitative analysis: The good, the bad, and the ugly. Journal of Chemical Education, 79(9), 1131.

Wood, C. (2006). The development of creative problem solving in chemistry. Chemistry Education Research and Practice, $7(2), 96-113$. 